Article

\title{
Estimation of the Amount of Disposed Antibiotics
}

\author{
Gabriela Cioca ${ }^{1}\left[\right.$ and Florentina-Daniela Munteanu ${ }^{2, *} \mathbb{( D}$ \\ 1 Preclinical Department, Faculty of Medicine, Lucian Blaga University of Sibiu, 550024 Sibiu, Romania; \\ gabriela.cioca@ulbsibiu.ro \\ 2 Faculty of Food Engineering, Tourism and Environmental Protection, Aurel Vlaicu University of Arad, \\ 310330 Arad, Romania \\ * Correspondence: florentina.munteanu@uav.ro; Tel.: +40-257283010
}

Received: 11 February 2019; Accepted: 20 March 2019; Published: 25 March 2019

check for updates

\begin{abstract}
The impact of the antibiotics in the environment is not well understood yet. Moreover, the total amount of antibiotics that are ending up in the environment as solid waste is not known and cannot be rigorously determined as many variables are influencing the determination of their concentration. The present article is focused on the estimation of the amount of non-prescribed antibiotics that are used in different European countries. Particular attention is paid to the class of beta-lactams, as they are responsible for a considerate share of the antimicrobial resistance. The primary purpose was the estimation of the quantity of non-prescribed antibiotics that might reach the environment as solid waste. For the present study, we used the ECDC and EUROSTAT reported data.
\end{abstract}

Keywords: antibiotics disposal; non-prescribed antibiotics; solid-waste

\section{Introduction}

Nowadays the use of personal care products and pharmaceuticals has led to an urgent problem due to their widespread presence in the environment. Moreover, the necessity to ensure public health has led to a tremendous increase in the number of active compounds that are used to prevent, treat, or ameliorate different human/animal diseases [1].

Out of all the used pharmaceuticals, antibiotics have a crucial role in the healthcare system. The antibiotics global production shows that they also have economic and societal importance [2].

This group of pharmaceuticals may be natural molecules, semi-synthetic, or synthetic products. Bacteria and fungi produce natural antibiotics (e.g., benzylpenicillin and gentamicin) and, generally, have a bacteriostatic or bactericidal effect. Semisynthetic ones are chemically modified natural antibiotics to increase their effectiveness in terms of pharmacokinetics, pharmacodynamics, or toxicological profile. Depending on the functional groups present in their chemical structure, antibiotics are classified into several classes: Beta-lactams, Macrolides, Tetracyclines, Quinolones, Aminoglycosides, Sulphonamides, Glycopeptides, and Oxazolidinones [3]. Figure 1 contains the structure of the most used antibiotics from different classes. 
(a)
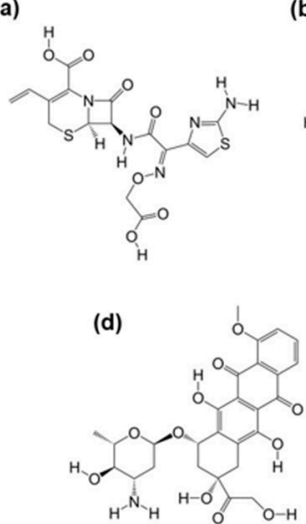

(b)

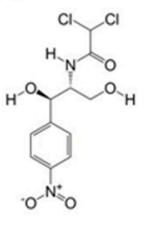

(c)

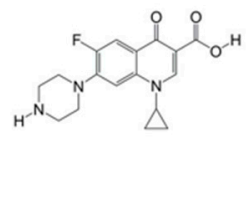

(f)

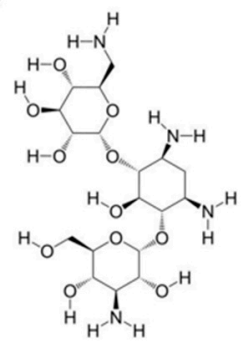

(e)

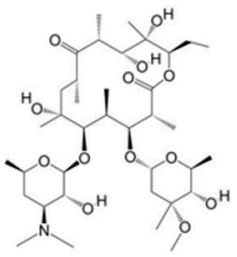

(g)

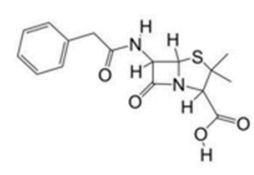

(h)

Figure 1. Structures of some of the most used antibiotics: (a) Cefixim-3rd class cephalosporin;

(b) Chloramphenicol-amphenicol; (c) Ciprofloxacin-2nd generation of Quinolones

(d) Epirubicin-antracycline; (e) Erithromycin-macrolides; (f) Kanamycin-Aminoglycosides;

(g) Peniciline-Beta-lactams; (h) Sulfadiazine-sulphonamides.

The increasing quantities of pharmaceuticals in the environment and the accumulation of antibiotics in the human body via the food chain pose important public health and eco-toxicity concerns [4]. Moreover, misuse of antibiotics leads to a decrease in the effectiveness of treatment of infectious diseases [5]. It is a well-known fact that between 30 and $90 \%$ of a dose of antibiotics for systemic use is excreted as an active substance [6] or in some case as active metabolites [7,8]. Finally, all of them reach the wastewater [9]. Moreover, the hospital's effluents that are discharged in the sewage without any prior treatment represent an important source of antibiotics in the wastewater treatment system. However, since most of the wastewater treatment plants are not designed to remove antibiotics or other pharmaceuticals compounds, they end up in the environment, especially in soil and water [10].

Therefore, the antibiotic resistance is becoming a subject of concern all over the world, and the infectious diseases are becoming more and more difficult to treat because of the development of new resistance mechanisms [5,6,11-18].

Despite these concerns, few countries recommend pre-treatment of the sewage effluents before their release into the environment, and the European Directive 91/271/EEC [19] for this particular category of waste does not foresee any restrictions. Moreover, current EU legislation does not include specific regulations, neither the potential presence of antibiotic-resistant bacteria and antibiotic-resistant genes in these waters nor their concentration thresholds.

Although the EU Commission Regulation No. 37/2010/EEC [20] has specifications regarding the maximum residue limits (MRLs) in foodstuffs of animal origin of some pharmacologically active substances, the amount of antibiotics that can reach the environment is not regulated.

Another worrying issue is the unsafe disposal of the prescribed and non-prescribed medicines, especially of antibiotics. A part of these medicines that are bought and finally not used for different reasons poses a risk to reach in the environment as solid waste. Not all the countries have a good 
well-established take-back system and some of them still dump the waste in landfills. In this context, environmental exposure to unused medicines becomes an important issue.

Penicillins are easily degraded, but other antibiotics are considerably more persistent, such as fluoroquinolones and tetracyclines. For this reason, the last ones persist much longer in the environment and accumulate to higher concentration over time. Recent studies have identified some of the persistent antibiotics at very slight ng/L levels in drinking water [21]. In a natural environment, exposure to clinical antibiotics had led to an increased number of resistant bacteria detected in the faeces of some species of wild animals [22,23]. To date, there is no clear evidence of the impact of these molecules on the ecosystem, and particularly, their influence on microorganisms that play an essential role in wastewater treatment.

The present study has in attention the presence of antibiotics in the environment, as their threats to all organisms and ecosystems are well-known. Therefore, it is focusing on the estimation of the quantity of the non-prescribed antibiotics that are reaching the environment as solid waste, and on the necessity of rigorous management of the disposed of antibiotics.

\section{Materials and Methods}

The primary objective of the present study is to estimate the antibiotic consumption in different countries from Europe and to estimate the consumption of the non-prescribed antibiotics as well as to estimate the amount of wasted antibiotics that can reach the environment.

The data about the consumption of the antibiotics and the number of the countries inhabitants were extracted from the European Centre for Disease Prevention and Control Database [24] due to the accessibility, validity, and reliability of the information.

The EUROSTAT databases were the source of the other data collected [25,26]. The references year was 2015, except the data for the used medicines that were for the year 2014.

The bed occupancy for each country was reported to 1000 inhabitants and was calculated based on the reported number of beds available in each country, the bed occupancy rate in the hospitals, and the population of each country [26].

For the estimation of the amount of the non-prescribed antibacterials for systemic use, the percentage of the self-reported use of non-prescribed medicines [26] and the values for the consumption of antibacterials for systemic use in the community [24] reported by each country were taken into account. The same approach was applied in the case of the estimation of the non-prescribed beta-lactams.

For the calculation of the total amount of wasted antibiotics in each country, the reported percentage of the prescribed medicines that were disposed as full packs or less than a quarter content, published in 2018 by Vogler et al. [27] were used. Based on these reported percentages and on the estimated amount of the non-prescribed antibacterials use, the total amount of disposed antibiotics could be calculated for each country.

\section{Results and Discussion}

It is well known that the hospital waste is produced from identifiable point sources, and in most of the cases, their impact on the environment is regulated by the governmental agencies [28].

Even though, in our studies, we were interested in comparing the consumption of antibacterials in hospitals, expressed as defined daily dose (DDD), from different European countries taking into account the number of occupied beds reported to 1000 of inhabitants (Figure 2). For a better presentation of these data, the consumption of antibacterials in hospitals was normalized by the number of occupied beds per 1000 inhabitants. 


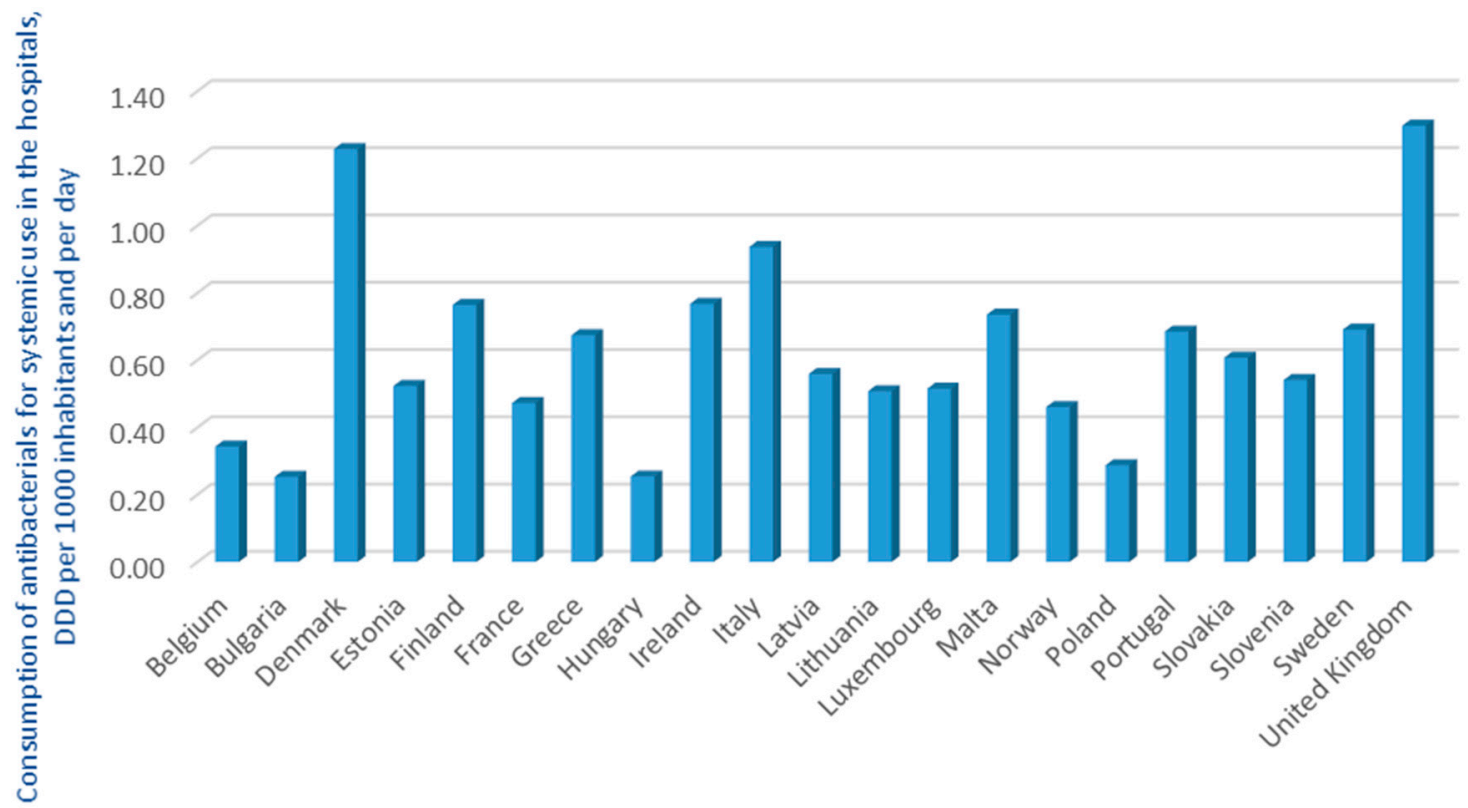

Figure 2. Consumption of antibacterials for systemic use in the hospital sector, expressed in defined daily dose (DDD) per 1000 inhabitants and per day. The values are normalized with the number of occupied beds per 1000 inhabitants.

There are significant differences between the approaches in each country concerning the consumption of the antibacterials in the hospitals reported to the number of occupied beds/1000 inhabitants. In some countries (Bulgaria, Denmark, Iceland, Netherlands, Norway, Poland, Romania, Sweden, and the United Kingdom), the bed occupancy in Eurostat was not found. For this reason, the comparison between different European countries was made by using $75 \%$ of bed occupancy, which is near to the average value calculated from all reported data for the other countries $(74.7 \%)$.

The estimating of antibiotics consumption in the hospital is essential for determining the amount of active compound that is wasted and reaches the environment. Hospital wasted antibiotics will add to some extent to the pharmaceutical load in the influent of the wastewater treatment plants (WWTPs) or to the amount of the antibiotics in the solid waste [29] that is contaminating the soil.

Therefore, it is essential to evaluate how significant is the contribution of the wasted antibiotics from the hospitals to environmental pollution with these contaminants. Moreover, future studies can be performed to evaluate the efficiency and effectiveness of hospital waste management.

Figure 3 presents the estimated consumption of the non-prescribed antibacterials for systemic use. The percentage of self-reported use of non-prescribed medicines [22] was the basis of obtaining the results. This percentage applied to the reported consumption of antibacterials for systemic use in the community expressed in DDD per 1000 inhabitants and per day in 2015. In this way, the values of the estimated consumption of non-prescribed antibiotics in different countries were obtained.

Figure 3 illustrates the significant differences between the consumption of different countries. These findings arise from the way of reporting the data. Some of them report the data for the primary care sector including the data from the hospital sector. However, in the case of some others, the percentage of self-reported use of non-prescribed medicines was less than half of the average values for all of the countries considered in the study. The average value was $39.3 \%$. 


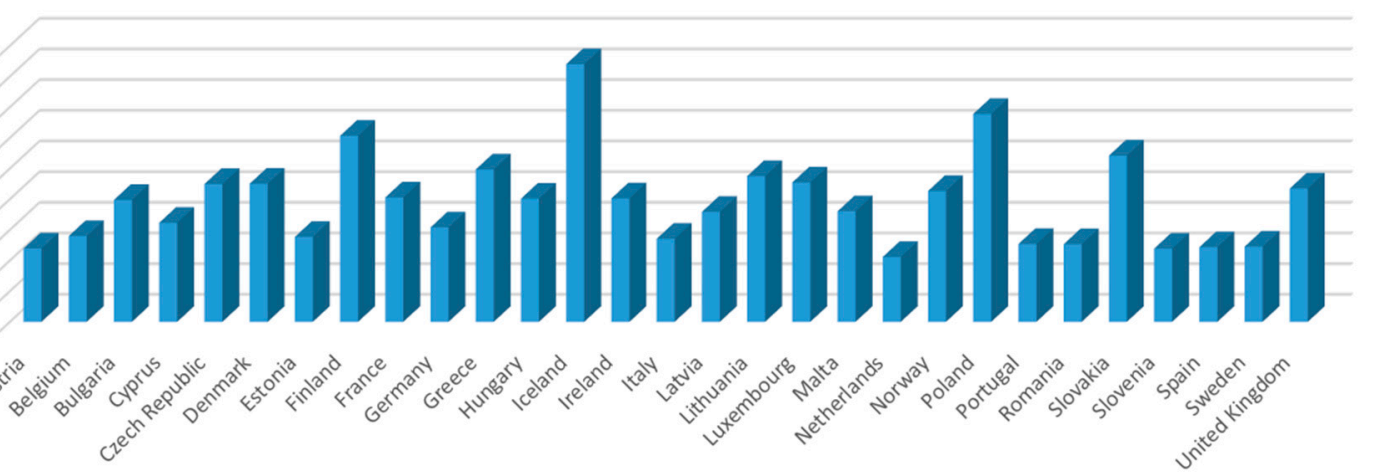

Figure 3. Estimated consumption of non-prescribed antibacterials for systemic use expressed in defined daily dose (DDD) per 1000 inhabitants.

Further prospective studies can be performed in order to evaluate the impact on the environment of the over the counter sold antibiotics that generally should not be retailed without a medical prescription.

In the same time, while doing the abovementioned prospective studies, information regarding the medicine take-back programs can be collected. These programs are designed to dispose of the expired and leftover medicines securely and to reduce the impact on the environment.

Beta-lactams are a class of antibiotics with the highest number of members that are approved by the Food and Drug Administration and represents an important class for human medicine [6,30]. In general, beta-lactam antibacterials are the most used antibiotics in hospitals.

The dose of the beta-lactams, as well as other classes of antibiotics, has a significant contribution to the evolution and spread of antimicrobial resistance.

In the present study, we wanted to estimate the consumption of this class of antibiotics in the case of non-prescribed medicine. As shown above, we were using the percentage of the self-reported use of non-prescribed medicines and assumed that the same value could be used to estimate the consumption of these antibiotics. Figure 4 shows these results and they correlate with the previously reported ones in most of the countries [31].

In a study performed in Vienna, Austria between April 2015 and January 2016, it was found that $15 \%$ of the non-prescribed medicines were disposed of as full packs, while $21 \%$ of the non-prescribed medications were disposed of as less than a quarter of a full pack. In our study, we decided to use these percentages and to calculate the total estimated amount that can reach in the environment as solid waste (Figure 5).

It must be emphasized that the presented results cannot make any assumption about the expiration date of the disposed of antibiotics.

Of course, based on the data available in the literature [32], further estimations can be performed in regards to the expiration date of the wasted antibiotics, but the most critical aspect remains the fact that an essential amount of non-prescribed antibiotics are daily disposed of and are contaminating the soil and therefore contributing to an increased microbial resistance. 


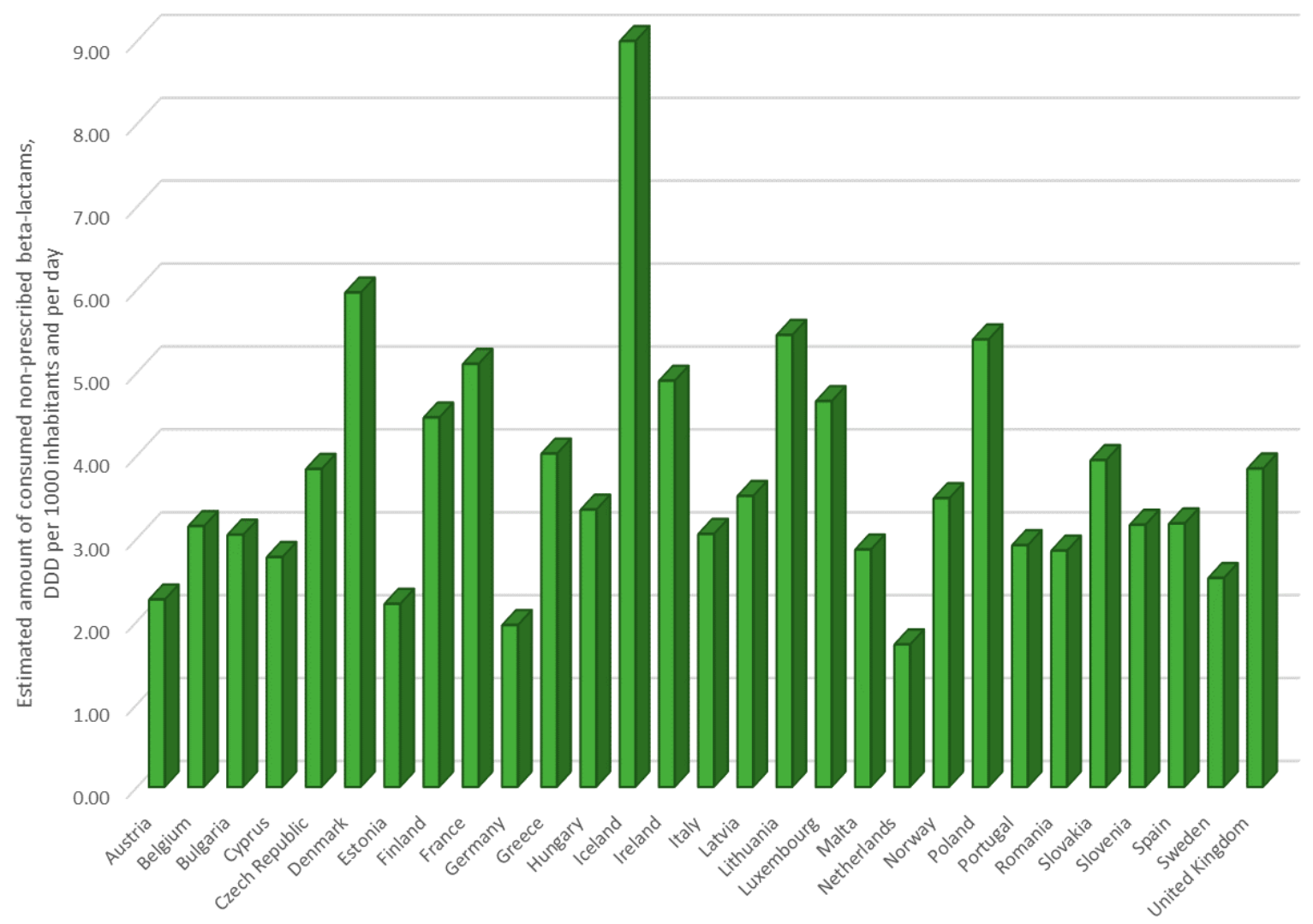

Figure 4. Estimated consumption of non-prescribed beta-lactams for systemic use expressed in defined daily dose (DDD) per 1000 inhabitants.

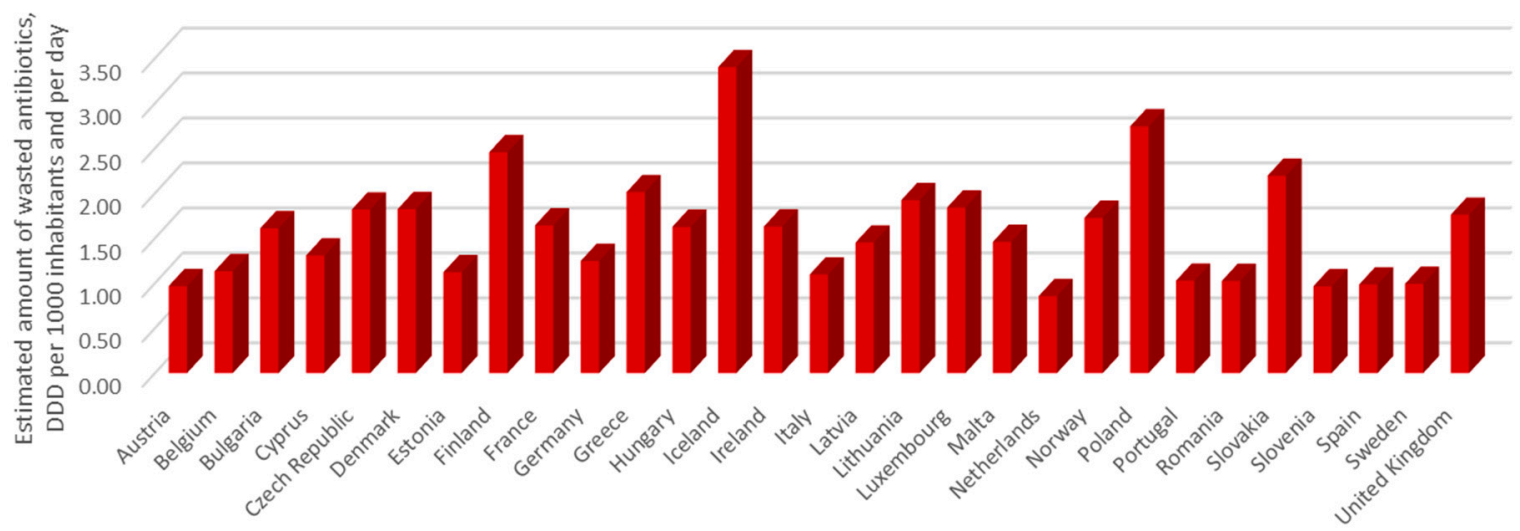

Figure 5. Estimated amount of wasted non-prescribed antibiotics expressed in defined daily dose (DDD) per 1000 inhabitants.

The Annual Report of the European Antimicrobial Resistance Surveillance Network (EARS-Net) [33], published in 2016, shows the situation on antimicrobial resistance. It was observed that in 2016 there is a wide variation between the European countries, but in general, the highest values are registered in the southern and eastern countries. In terms of human bacterial resistance, published in the abovementioned report, more than half of Escherichia coli strains (58.6\%), Acinetobacter genus $(55.4 \%)$, and one-third of the Klebsiella pneumoniae strains (34.5\%) are resistant to at least one group of antibiotics (aminopenicillins, fluoroquinolones, third-generation cephalosporins, aminoglycosides, and carbapenems). Pseudomonas aeruginosa, a non-fermentative gram-negative bacterium, commonly found in the aquatic environment, is an opportunistic pathogen for humans, mainly producing 
nosocomial infections. In the EU, one-third of the reported strains (33.9\%) in EARS-Net in 2016 were resistant to at least one antibiotic group (piperacillin \pm tazobactam, fluoroquinolones, ceftazidime, aminoglycosides, and carbapenems).

For the estimation of the amount of antibiotics that reach the environment, we were considering the share of $15 \%$ of the non-prescription medicines disposed of as full packs and that $21 \%$ of non-prescription medicines had less than a quarter content. The results presented in Figure 5 are similar for all considered countries and in most cases do not have values higher than 2.50 DDD per 1000 inhabitants. Exceptions are just in three cases, where the values are over this value.

\section{Conclusions}

In this paper, the total amount of antibiotics that might reach the environment as solid waste was estimated. As it can be observed, the amount of trashed antibiotics is not higher than 2.5 DDD per 1000 inhabitants, but this situation can get worse if proper take-back programs are not properly implemented.

There are still further studies to be performed in order to assess the impact of these contaminants on the environment, especially at the level of the microbial community due to the selection of resistant bacteria and disappearance or inhibition of another microbial group. All of this may directly affect ecosystem processes.

As a general conclusion, the findings presented in this paper urge for the creation of an awareness program in all relevant fields in order to contribute to the environmental risk reduction of the disposed of antibiotics.

However, the most critical aspect is to consider the development of advanced options for the management of the wasted antibiotics and in this context, it is imperative to develop studies to improve their degradation in the first place into wastewater treatment plants. Moreover, intensive awareness programs designed for specialists as well as for the consumers are necessary to be developed in the near future in order to diminish the impact of the medicine discarded in the household garbage.

Author Contributions: G.C. and F.-D.M., had equal contributions to the drafting of the manuscript. Conceptualization, Data curation, Formal analysis, and Methodology, G.C. and F.-D.M.; Writing-original draft, G.C.; Writing-review \& editing, F.-D.M.

Funding: Project financed from “Lucian Blaga” University of Sibiu research grant LBUS-IRG-2016-02.

Acknowledgments: G.C. acknowledges the financial support from "Lucian Blaga" University of Sibiu, grant number LBUS-IRG-2016-02.

Conflicts of Interest: The authors declare no conflict of interest.

\section{References}

1. Ierapetritou, M.; Muzzio, F.; Reklaitis, G. Perspectives on the continuous manufacturing of powder-based pharmaceutical processes. AlChE J. 2016, 62, 1846-1862. [CrossRef]

2. O'Neill, J. Securing New Drugs for Future Generations: The Pipeline of Antibiotics; Wellcome Trust: London, UK, 2015.

3. Adzitey, F. Antibiotic classes and antibiotic susceptibility of bacterial isolates from selected poultry: A mini review. World Vet. J. 2015, 5, 36-41. [CrossRef]

4. Aghdam, E.M.; Hejazi, M.S.; Barzegar, A. Riboswitches: From living biosensors to novel targets of antibiotics. Gene 2016, 592, 244-259. [CrossRef]

5. Leibovici, L.; Paul, M.; Garner, P.; Sinclair, D.J.; Afshari, A.; Pace, N.L.; Cullum, N.; Williams, H.C.; Smyth, A.; Skoetz, N.; et al. Addressing resistance to antibiotics in systematic reviews of antibiotic interventions. J. Antimicrob. Chemother. 2016, 71, 2367-2369. [CrossRef]

6. Fair, R.J.; Tor, Y. Antibiotics and bacterial resistance in the 21st century. Perspect Med. Chem. 2014, 6, 25-64. [CrossRef]

7. Grenni, P.; Ancona, V.; Caracciolo, A.B. Ecological effects of antibiotics on natural ecosystems: A review. Microchem. J. 2018, 136, 25-39. [CrossRef] 
8. Kemper, N. Veterinary antibiotics in the aquatic and terrestrial environment. Ecol. Indic. 2008, 8, 1-13. [CrossRef]

9. Louvet, J.N.; Giammarino, C.; Potier, O.; Pons, M.N. Adverse effects of erythromycin on the structure and chemistry of activated sludge. Environ. Pollut. 2010, 158, 688-693. [CrossRef]

10. Carvalho, I.T.; Santos, L. Antibiotics in the aquatic environments: A review of the European scenario. Environ. Int. 2016, 94, 736-757. [CrossRef]

11. Berendonk, T.U.; Manaia, C.M.; Fatta-Kassinos, D.; Cytryn, E.; Walsh, F.; Bürgmann, H.; Sørum, H.; Norström, M.; Pons, M.-N.; Kreuzinger, N.; et al. Tackling antibiotic resistance: The environmental framework. Nat. Rev. Microbiol. 2015, 13, 310. [CrossRef]

12. Anthony, A.A.; Adekunle, C.F.; Thor, A.S. Residual antibiotics, antibiotic resistant superbugs and antibiotic resistance genes in surface water catchments: Public health impact. Phys. Chem. Earth Parts A/B/C 2018, 105, 177-183. [CrossRef]

13. Kim, Y.B.; Jeon, J.H.; Choi, S.; Shin, J.; Lee, Y.; Kim, Y.M. Use of a filtering process to remove solid waste and antibiotic resistance genes from effluent of a flow-through fish farm. Sci. Total Environ. 2018, 615, 289-296. [CrossRef]

14. Le Page, G.; Gunnarsson, L.; Snape, J.; Tyler, C.R. Integrating human and environmental health in antibiotic risk assessment: A critical analysis of protection goals, species sensitivity and antimicrobial resistance. Environ. Int. 2017, 109, 155-169. [CrossRef]

15. Meyer, E.; Gastmeier, P.; Deja, M.; Schwab, F. Antibiotic consumption and resistance: Data from Europe and Germany. Int. J. Med. Microbiol. 2013, 303, 388-395. [CrossRef]

16. Sivagami, K.; Vignesh, V.J.; Srinivasan, R.; Divyapriya, G.; Nambi, I.M. Antibiotic usage, residues and resistance genes from food animals to human and environment: An Indian scenario. J. Environ. Chem. Eng. 2018. [CrossRef]

17. Szekeres, E.; Baricz, A.; Chiriac, C.M.; Farkas, A.; Opris, O.; Soran, M.L.; Andrei, A.S.; Rudi, K.; Balcazar, J.L.; Dragos, N.; et al. Abundance of antibiotics, antibiotic resistance genes and bacterial community composition in wastewater effluents from different Romanian hospitals. Environ. Pollut. 2017, 225, 304-315. [CrossRef]

18. Wu, D.; Huang, Z.; Yang, K.; Graham, D.; Xie, B. Relationships between antibiotics and antibiotic resistance gene levels in municipal solid waste leachates in Shanghai, China. Environ. Sci. Technol. 2015, 49, 4122-4128. [CrossRef]

19. Council Directive 91/271/EEC of 21 May 1991 concerning urban waste-water treatment.

20. European Commission Decision 37/2010. Off. J. Eur. Commun. 2010, 15, 1-72.

21. Ye, Z.; Weinberg, H.S.; Meyer, M.T. Trace analysis of trimethoprim and sulfonamide, macrolide, quinolone, and tetracycline antibiotics in chlorinated drinking water using liquid chromatography electrospray tandem mass spectrometry. Anal. Chem. 2007, 79, 1135-1144. [CrossRef] [PubMed]

22. Larsson, D.G. Antibiotics in the environment. Ups. J. Med. Sci. 2014, 119, 108-112. [CrossRef] [PubMed]

23. Van Schaik, W.; Cristóbal-Azkarate, J.; Dunn, J.C.; Day, J.M.W.; Amábile-Cuevas, C.F. Resistance to antibiotics of clinical relevance in the fecal microbiota of Mexican wildlife. PLoS ONE 2014, 9, e107719.

24. European Centre for Disease Prevention and Control. An Agency of the European Union. 2016. Available online: https: / ecdc.Europa.Eu/en/antimicrobial-consumption/surveillance-and-disease-data/database (accessed on 30 June 2018).

25. European Commission, Eurostat. Available online: http://ec.Europa.Eu/eurostat/statistics-explained/ index.Php/medicine_use_statistics (accessed on 30 June 2018).

26. European Commission, Eurostat. Available online: http://ec.Europa.Eu/eurostat/statistics-explained/ index.Php/healthcare_resource_statistics_-_beds (accessed on 30 June 2018).

27. Vogler, S.; de Rooij, R. Medication wasted-Contents and costs of medicines ending up in household garbage. Res. Soc. Adm. Pharm. 2018, 14, 1140-1146. [CrossRef] [PubMed]

28. Gajalakshmi, S.; Abbasi, S.A. Solid waste management by composting: State of the art. Crit. Rev. Environ. Sci. Technol. 2008, 38, 311-400. [CrossRef]

29. Du, L.; Liu, W. Occurrence, fate, and ecotoxicity of antibiotics in agro-ecosystems. A review. Agron. Sustain. Dev. 2011, 32, 309-327. [CrossRef]

30. Opatowski, L.; Mandel, J.; Varon, E.; Boëlle, P.-Y.; Temime, L.; Guillemot, D. Antibiotic dose impact on resistance selection in the community: A mathematical model of $\beta$-lactams and streptococcus pneumoniae dynamics. Antimicrob. Agents Chemother. 2010, 54, 2330-2337. [CrossRef] [PubMed] 
31. Kritsotakis, E.I.; Christidou, A.; Roumbelaki, M.; Tselentis, Y.; Gikas, A. The dynamic relationship between antibiotic use and the incidence of vancomycin-resistant enterococcus: Time-series modelling of 7-year surveillance data in a tertiary-care hospital. Clin. Microbiol. Infect. 2008, 14, 747-754. [CrossRef] [PubMed]

32. Paut Kusturica, M.; Tomas, A.; Sabo, A. Disposal of unused drugs: Knowledge and behavior among people around the world. In Reviews of Environmental Contamination and Toxicology; de Voogt, P., Ed.; Springer International Publishing: Cham, Switzerland, 2017; Volume 240, pp. 71-104.

33. European Centre for Disease Prevention and Control. Antimicrobial resistance surveillance in Europe 2016. Annual Report of the European Antimicrobial Resistance Surveillance Network (EARS-Net); European Centre for Disease Prevention and Control: Stockholm, Sweden, 2017.

(C) 2019 by the authors. Licensee MDPI, Basel, Switzerland. This article is an open access article distributed under the terms and conditions of the Creative Commons Attribution (CC BY) license (http:/ / creativecommons.org/licenses/by/4.0/). 